Tạp chí Khoa học và Công nghệ biển T10 (2010). Số 4. Tr 87 - 95

\title{
ẢNH HƯỞNG CỦA MẬT ĐỘ LÊN SỰ SINH TRƯỞNG VÀ TỈ LỆ SỐNG \\ CỦA CÁ NGỰA VẰN (HIPPOCAMPUS COMES, CANTOR, 1850) Ở VÙNG BIỂN KHÁNH HÒA
}

\author{
TRƯƠNG SĨ KỲ, HOÀNG ĐỨC LƯ, HỒ THỊ HOA \\ Viện Hải dương học \\ PHẠM VŨ LÃNG \\ Sinh viên cao học ĐHTH Huế
}

\begin{abstract}
Tóm tắt: Thí nghiệm ảnh hwởng của mật độ nuôi lên sụ sinh truơng và tỉ lệ sống của cá ngụa vằn được tiến hành trong thời gian105 ngày. Chiều dài cá thí nghiệm bắt đầu là $39,06 \mathrm{~mm}, 39,26 \mathrm{~mm}$ và 39,73 mm (P> 0,05) ở úng với lô thủ nghiệm nuôi $50 \mathrm{con} / 150$ lít (lô 1), 100 con/150 lít (lô 2) và 150 con/ 150 con (lô 3). Sau 105 ngày nuôi thí nghiệm, cá đạt chiều dài 94,40 mm, 89,95 mm và 91,00 mm ở lô 1 , lô 2 và lô 3.

Sụ tăng trương của cá nuôi ở mật độ 50 con/ 150 lít (lô 1) nhanh hơn so với cá ở lô 2 và lô $3(P<0,05)$. Tỉ lệ sống của cá nuôi ở các bể thí nghiệm đều lớn hơn $96 \%$. Nghiên cúu này đã chứng tỏ rằng nuôi cá ngựa ở mật độ 1 con trên 3 lít nước biển là tốt nhất.
\end{abstract}

\section{MỞ ĐẦU}

Cá ngựa vằn hay còn gọi là cá ngựa Đuôi hổ (Tiger tail seahorse) phân bố chủ yếu ở vùng biển nhiệt đới: Philippiness, Malaysia, Thái Lan và Việt Nam (Lourie và cộng sự, 1999) thường gặp ở độ sâu 5 - 10 m (Morgan và Lourie, 2006), ít khi gặp ở độ sâu 20m (Kuiter, 2000). Ở Việt Nam, chúng chỉ mới phát hiện ở vùng biển Khánh Hòa và Phú Yên, những nơi có rạn san hô phân bố. Phương tiện khai thác chủ yếu là lặn bắt hoặc đánh lưới giã cào. Cá thường được bán ở dạng sống, khô và tươi với mục đích ngâm rượu hoặc làm thuốc để chữa một số bệnh như vô sinh, hen suyển... (Đỗ Tất Lợi, 1977)

Trong thời gian gần đây, Viện Hải dương học đã thử nghiệm nuôi thành công loài cá này và đã xuất khẩu sang các nước châu Âu và Mỹ với mục đích nuôi cá cảnh. Tuy số lượng nuôi chưa nhiều, nhưng tiềm năng xuất khẩu cá ngựa nói chung và cá ngựa vằn nói riêng là khá lớn và đạt lợi nhuận cao. Giá cá ngựa nuôi cảnh ở Hawaii giao động từ 70 300 USD/ con tùy theo loài và kích thước. (www.seahorse.com). Cho đến nay, theo các tài 
liệu mà chúng tôi có được, Việt Nam là nước đầu tiên thành công cho sinh sản nhân tạo loài cá này. Đồng thuận với nhận xét này là là ý kiến của Foster và Vincent (2004).

Nghiên cứu về đặc điểm sinh học và phân loại loài cá này chưa nhiều. Năm 1996, Peranter và cộng sự nghiên cứu đặc điểm sinh học của chúng ở đảo Jadayan (Philippines), kết quả cho thấy $\mathrm{L} \infty$ đạt $203 \mathrm{~mm}$ và hệ số tăng trưởng $\mathrm{k}=1,7 /$ năm. Đây là loài cá đẻ quanh năm nhưng sản lượng khai thác cá con cao từ tháng 3 đến tháng 4 , ở những nơi có nhiều rong mơ (Sargassum). Cá trưởng thành bị khai thác nhiều ở sinh cảnh là san hô và bọt biển (Sponges). Cá ngựa vằn đang có nguy cơ khai thác quá mức và nghề cá ven bờ là mối đe dọa cho nguồn lợi của loài cá này (Morgan và Vincent, 2007).

Cá ngựa vằn thay đổi sinh cảnh (macrohabitat) và giá bám (microhabitat) phụ thuộc vào quá trình phát triển cá thể (Morgan và Vincent, 2007). Cá trưởng thành phân bố chủ yếu ở rạn san hô, nhưng con non (juvenile) thường bắt gặp ở thảm rong mơ. Giá thể bám của cá con là các nhánh rong, trong khi đó đối với cá lớn là cành san hô hoặc bọt biển. Đây là loài hoạt động về đêm (Peranter và cộng sự, 1996; Morgan và Lourie, 2006) và mật độ quần thể ngoài tự nhiên rất thấp, khoảng 0,019 cá thể $\mathrm{m}^{-2}$ (Peranter và cộng sự, 2002). Kích thước thành thục sinh dục của cá đực là 96 mm (Standard Lenght) (tương đương với chiều cao $78 \mathrm{~mm}$ (Height: chiều dài từ mút đuôi đến mào đầu), nhưng cá thể mang phôi có chiều dài chuẩn (SL) là 105 mm (tương đương với chiều cao $87 \mathrm{~mm}$ ) (Morgan và Lourie, 2006).

Sản lượng khai thác cá ngựa nói chung, cá ngựa vằn nói riêng càng ngày càng giảm (Vincent, 1996; Perante và cộng sự, 2002), cho nên hầu hết các loài cá ngựa đều nằm trong danh mục của CITES, phụ lục II. Ở Việt Nam, chúng nằm trong Sách Đỏ ở mức độ “có nguy cơ bị đe dọa” (Nguyễn Hữu Phụng, 1992).

Nghiên cứu về ảnh hưởng của mật độ lên sự sinh trưởng cá ngựa Hippocampus abdominalis và $H$. whitei có công trình của Woods (2003), Woong và Benzie (2003). Đến nay chưa có công trình nào nghiên cứu về mối liên hệ giữa mật độ nuôi, sự tăng trưởng và tỉ lệ sống của cá ngựa vằn.

Mục đích của bài viết này là cung cấp số liệu về mật độ nuôi thích hợp của cá ngựa Vằn, làm cơ sở cho việc hoàn thiện qui trình nuôi loài cá quí hiếm này.

\section{PHƯƠNG PHÁP NGHIÊN CÚU}

Cá được nuôi thí nghiệm trong bể kính 150 lít với mật độ là 50 con (lô 1), 100 con (lô 2) và 150 con / bể (lô 3). Thí nghiệm được tiến hành 2 lần. Phương pháp cho ăn, thay nước và vệ sinh giữa các bể được xây dựng trong điều kiện tương đồng nhất có thể. 
Thức ăn của cá là Mysis spp. đông lạnh, cho ăn ngày 2 lần: 8 giờ và 16 giờ, theo chế độ bão hòa. Tất cả các loại thức ăn đều được diệt khuẩn bằng ozone, $220 \mathrm{mg} /$ giờ trong 15 phút.

Thức ăn thừa và phân được hút ra , bổ sung lượng nước mất đi hằng ngày, thay $1 / 2$ nước hằng tuần. Thiết kế lọc sinh học bằng san hô với thể tích bằng $1 / 3$ hệ thống bể nuôi. Tỉ lệ lọc nước ngày đêm của bể nuôi là $300 \%$ - 500\%.

Cân và đo cá theo phương pháp của Lourie và cộng sự (1999) sau 15 ngày, tính tỉ lệ sống và hệ số $\mathrm{k}$ (hệ số độ béo, $\mathrm{k}=\mathrm{W} / \mathrm{L}^{3}$ ) của cá lúc kết thúc thí nghiệm. Yếu tố môi trường của bể nuôi như sau:

Độ muối $30-35$ ppt

Oxy $4-5$ ppm

pH $8-8.3$

Ammonia $0-0,5$ ppm

Nitrite 0 ppm

Nitrate $<20 \mathrm{ppm}$

Số liệu được xử lý bằng phần mềm Excel, sử dụng ANOVA và Tukey test,... để phân tích và đánh giá sự khác biệt của số liệu.

\section{KẾT QUẢ NGHIÊN CÚU VÀ THẢO LUẬN}

Như đã trình bày trong phần phương pháp nghiên cứu, cá được nuôi với mật độ 50 con (lô 1) 100 con (lô 2) và 150 con/ bể 150 lít (lô 3), cá thí nghiệm có chiều dài tương ứng ban đầu là $63,73 \mathrm{~mm} ; 62,60 \mathrm{~mm} ; 62,43 \mathrm{~mm}$. Kết thúc thí nghiệm, cá đạt chiều dài ở các lô 1,2, và 3 theo thứ tự như sau 75,20 mm; 74,53 mm và 74,5 mm (bảng 1). Trong đợt thí nghiệm này cá bị bệnh lở đuôi, phải xử lý cá bằng kháng sinh. Tỉ lệ chết khá cao và thí nghiệm chỉ tiến hành được 45 ngày. Có thể thấy sự tăng trưởng về kích thước của cá ở các lô thí nghiệm là khác nhau không rõ rệt $(\mathrm{P}>0,05)$, nhưng tỉ lệ sống thấp nhất ở lô nuôi cá có mật độ cao nhất. Điều này phù hợp với lý thuyết khi nuôi với mật độ cao thì khả năng lây bệnh càng lớn, tỉ lệ chết càng cao. 
Bảng 1: Tăng trưởng theo chiều cao $(\mathrm{mm})$ của cá ngựa Vằn theo mật độ nuôi (Thí nghiệm lần thứ nhất)

\begin{tabular}{|c|c|c|c|}
\hline Ngày & Lô 1 & Lô 2 & Lô 3 \\
\hline 1 & 63,73 & 62,60 & 62,43 \\
\hline 15 & 67,63 & 67,06 & 66,53 \\
\hline 30 & 72,26 & 72,06 & 69,1 \\
\hline 45 & 75,20 & 74,53 & 74,50 \\
\hline Tỉ lệ sống (\%) & 70 & 70 & 57 \\
\hline
\end{tabular}

Thí nghiệm về ảnh hưởng của mật độ lên tỉ lệ sống và tăng trưởng của cá ngựa Vằn được tiến hành lần thứ 2 . Cá có chiều dài ban đầu là $39,06,39,26$ và $39,73 \mathrm{~mm}$ tương ứng với lô 1 , lô 2 và lô 3 . Sau 105 ngày nuôi, cá đạt kích thước ở lô 1 , lô 2 và lô 3 là $94,40 \mathrm{~mm} ; 89,95 \mathrm{~mm}$ và $91,00 \mathrm{~mm}$ (bảng 2, hình 1 ). Khối lượng của cá nuôi thí nghiệm được trình bày ở bảng 3 , hình 2 .

Bảng 2: Tăng trưởng theo chiều cao $(\mathrm{mm})$ và \pm sd của cá ngựa Vằn theo mật độ nuôi (Thí nghiệm lần thứ hai)

\begin{tabular}{|c|c|c|c|}
\hline Ngày thí nghiệm & Lô 1 & Lô 2 & Lô 3 \\
\hline 1 & $39,06 \pm 1,72$ & $39,26 \pm 2,03$ & $39,73 \pm 1,83$ \\
\hline 15 & $51,10 \pm 3,88$ & $48,10 \pm 2,03$ & $47,53 \pm 3,11$ \\
\hline 30 & $56,65 \pm 5,86$ & $51,30 \pm 2,32$ & $54,45 \pm 4,92$ \\
\hline 45 & $68,85 \pm 6,64$ & $61,15 \pm 2,61$ & $65,25 \pm 3,64$ \\
\hline 60 & $73,70 \pm 5,61$ & $70,20 \pm 3,13$ & $72,00 \pm 5,16$ \\
\hline 75 & $86,40 \pm 6,91$ & $79,75 \pm 5,14$ & $82,5 \pm 5,47$ \\
\hline 90 & $86,70 \pm 6,02$ & $81,35 \pm 6,02$ & $82,9 \pm 5,97$ \\
\hline 105 & $94,40 \pm 4,94^{\mathrm{a}}$ & $89,95 \pm 4,28^{\mathrm{b}}$ & $91,00 \pm 5,42^{\mathrm{b}}$ \\
\hline Tỉ lệ sống $(\%)$ & 98,00 & 99,00 & 96,00 \\
\hline
\end{tabular}

Các ký tụ a, b chỉ sư sai khác có ý nghĩa $(P<0,05)$

Tỉ lệ sống cao nhất là cá ở lô 1,2 và thấp nhất là lô thí nghiệm số 3 . Có thể thấy sự 
chênh lệch về kích thước cá và tỉ lệ sống của cá ở các lô thí nghiệm là không nhiều. Tuy nhiên, với mật độ nuôi 50 con/ 150 lít, cá tăng trưởng nhanh nhất và sai khác có ý nghĩa so với mật độ nuôi 100 và 150 con/ 150 lít. Wong và Benzie (2003) khi nghiên cứu loài Hippocampus whitei cho rằng, không có sự khác biệt rõ ràng về tỉ lệ sống và tốc độ tăng trưởng giữa 2 mật độ nuôi 0,5 - 1 con/lít. Tuy nhiên, mật độ nuôi càng nhỏ thì chỉ số GSI (Chỉ số sinh dục) càng lớn, điều này chứng tỏ rằng nuôi mật độ cao ( $\geq 1$ con/lít) có thể kiềm hãm sự phát triển tuyến sinh dục của cá ngựa nuôi. Woods (2003) cũng nghiên cứu loài $H$. abdominalis và cho rằng mật độ nuôi càng lớn thì khả năng sinh sản càng giảm và tỉ lệ chết tăng. Kết quả nuôi với 3 mật độ 1,2 và 5 con/ lít cho thấy mật độ nuôi tốt nhất là 1 con/ lít. Như vậy, mặc dù phương pháp nuôi và đối tượng nuôi là những loài cá ngựa khác nhau, nhưng hầu hết các tác giả đều thống nhất là nên nuôi cá ngựa với mật độ 0,3 1 con/lít. Về khía cạnh sinh học đây là kết luận khá hợp lý, nhưng về mặt kinh tế khi nuôi với mật độ thấp, giá thành sản xuất sẽ cao hơn. Do đó cần phải nghiên cứu bổ sung mối quan hệ về hiệu quả kinh tế và năng suất vật nuôi để có thể đề ra mật độ nuôi thích hợp nhất ở cả hai khía cạnh nêu trên.

Bảng 3: Tăng trưởng theo khối lượng $(\mathrm{g})$ của cá ngựa Vằn theo mật độ nuôi

\begin{tabular}{|c|c|c|c|}
\hline Ngày & Lô $\mathbf{~}$ & Lô 2 & Lô 3 \\
\hline 1 & 0,19 & 0,20 & 0,20 \\
\hline 15 & 0,38 & 0,34 & 0,32 \\
\hline 30 & $0,50 \pm 0,16$ & $0,37 \pm 0,07$ & $0,46 \pm 0,12$ \\
\hline 45 & $0,95 \pm 0,26$ & $0,66 \pm 0,10$ & $0,81 \pm 0,13$ \\
\hline 60 & $1,12 \pm 0,28$ & $1,02 \pm 0,19$ & $1,02 \pm 0,23$ \\
\hline 75 & $1,84 \pm 0,39$ & $1,52 \pm 0,25$ & $1,59 \pm 0,29$ \\
\hline 90 & $2,07 \pm 0,36$ & $1,74 \pm 0,31$ & $1,73 \pm 0,38$ \\
\hline 105 & $2,52 \pm 0,30$ & $2,12 \pm 0,30$ & $2,35 \pm 0,33$ \\
\hline
\end{tabular}

Hệ số độ béo k của cá giữa các lô thí nghiệm sai khác không có ý nghĩa (P > 0,05) (bảng 3 , hình 3 ). Chúng giao động từ $0,29-0,31$ và không chênh lệch nhiều theo thời gian tăng trưởng của cá. Như vậy, mật độ nuôi không ảnh hưởng đến độ béo của cá ngựa, tuy nhiên kết luận này chỉ đúng với cá chưa thành thục sinh dục. Nếu nuôi vỗ để cá tái phát dục và tham gia sinh sản, cần nuôi với mật độ nhỏ hơn 1 con/1lít (Woods, 2003). 


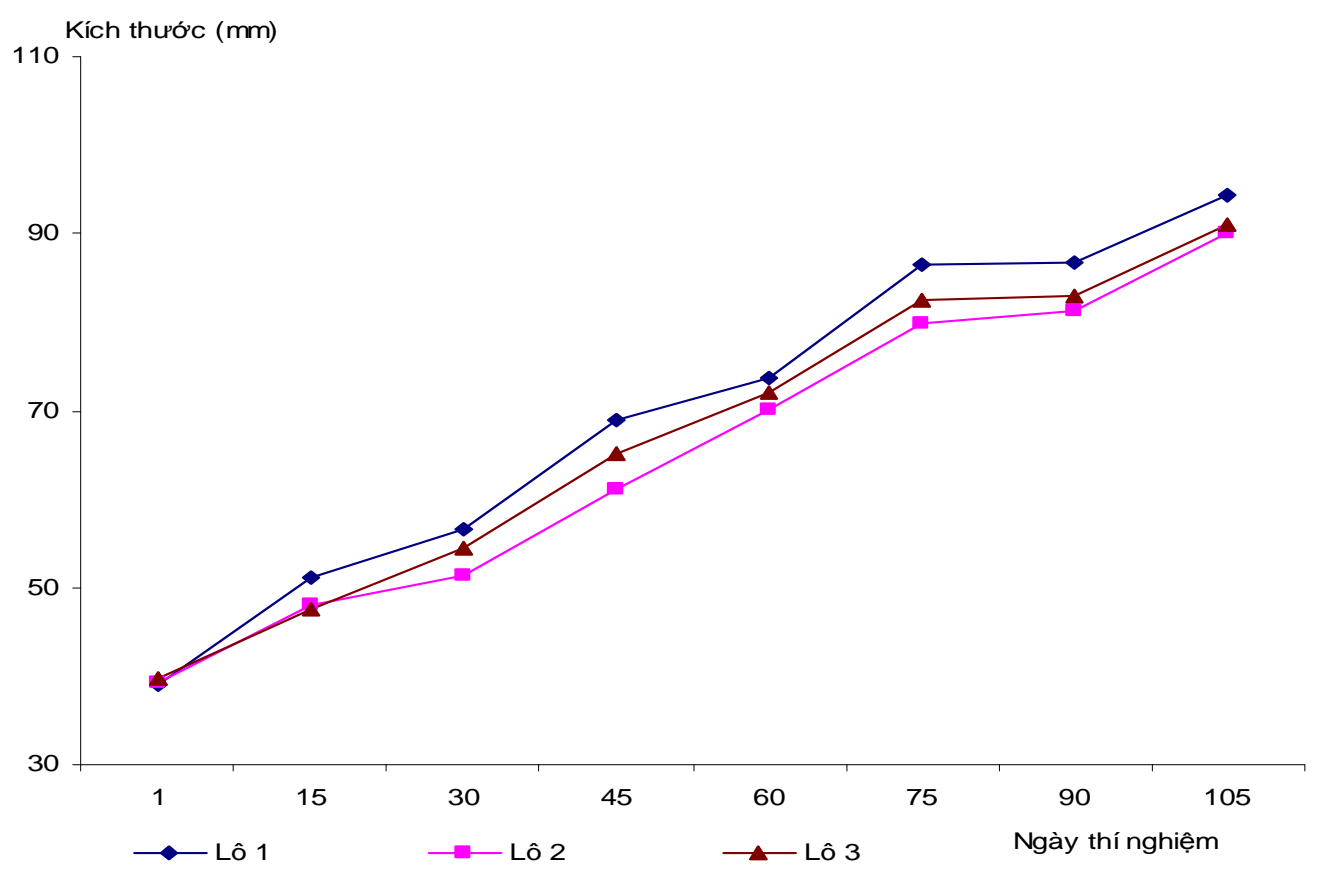

Hình 1: Tăng trưởng theo chiều cao $(\mathrm{mm})$ của cá ở các lô thí nghiệm khác nhau

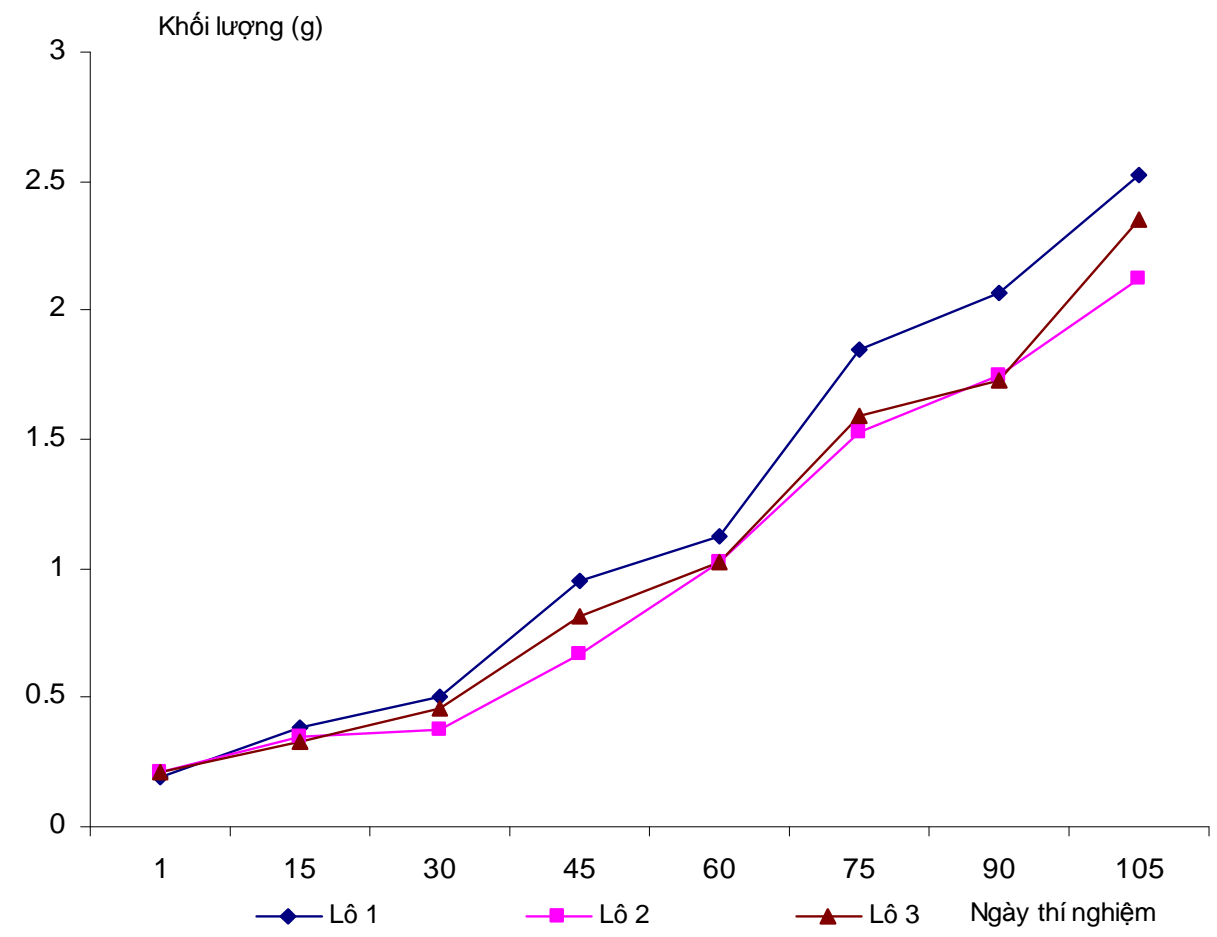

Hình 2: Tăng trưởng khối lượng (g) của cá ở các lô thí nghiệm khác nhau 
Bảng 3: Độ béo của cá ở các lô thí nghiệm

\begin{tabular}{|c|c|c|c|}
\hline Ngày thí nghiệm & Lô 1 & Lô 2 & Lô 3 \\
\hline 1 & 0.32 & 0.34 & 0.33 \\
\hline 15 & 0.30 & 0.31 & 0.31 \\
\hline 30 & 0.26 & 0.27 & 0.27 \\
\hline 45 & 0.28 & 0.29 & 0.29 \\
\hline 60 & 0.27 & 0.29 & 0.27 \\
\hline 75 & 0.28 & 0.29 & 0.28 \\
\hline 90 & 0.31 & 0.32 & 0.29 \\
\hline 105 & 0.30 & 0.29 & 0.31 \\
\hline
\end{tabular}

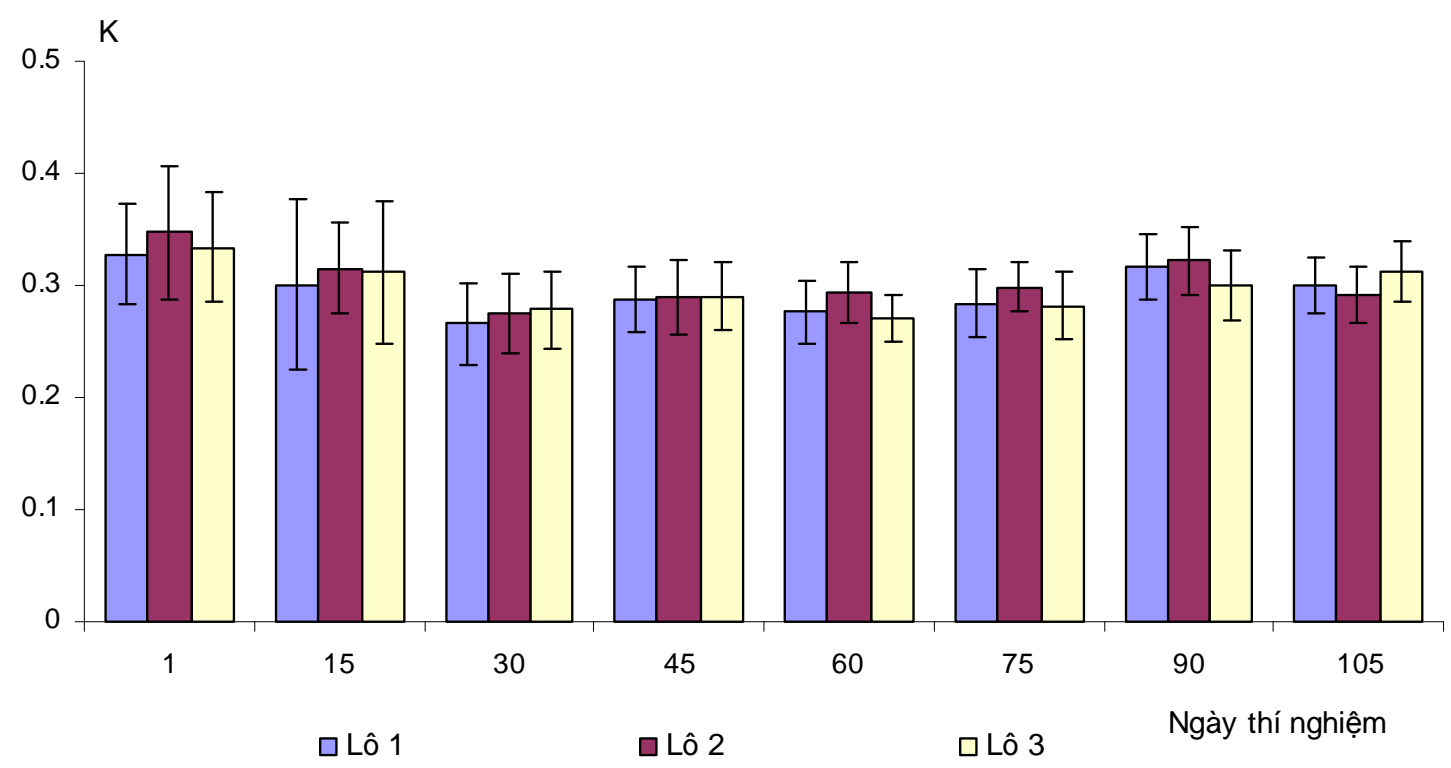

Hình 3: Độ béo $(\mathrm{k})$ của cá ở các lô thí nghiệm khác nhau

Lời cảm ơn: Xin chân thành cám ơn ban chủ nhiệm chương đề tài Nhà nước Cá cảnh KC 06.05/06 -10 đã tạo điều kiện để chúng tôi thực hiện các nội dung nghiên cứu về mật độ nuôi của cá ngựa vằn. Chúng tôi xin cám ơn KS. Hứa Thái Tuyến đã thống kê và xử lý số liệu cho bài viết này. 


\section{TÀI LIỆU THAM KHẢO}

1. Đỗ Tất Lợi, 1977. Những cây thuốc và vị thuốc Việt Nam. NXB Khoa học Kỹ thuật, Hà Nội.

2. Kuiter R. H., 2000. Seahorse, Pipefish and their relatives: A comprehensive Guide to Syngnathiformes. Chorlewood: TMC Publishing.

3. Lourie, S. A., J. C. Pritchard., S. P Casey., T. S Ky., H. J. Hall \& A. C. J.Vincent, 1999. The taxonomy of Vietnam's exploited seahorses (family Syngnathidae). Biological Journal of the Linnean Society 66: 231-256.

4. Morgan S.K. and S. A. Lourie, 2006. Threatened fishes of the world: Hippocampus comes Cantor 1850.(Sygnathidae) Environmental Biology of Fish 75: 311-313.

5. Morgan S.K. and A.C.J. Vincent, 2007. The ontogeny of habitat associations in the tropical tiger tail seahorse Hippocampus comes Cantor, 1850. Journal of Fish biology 71: 701-724.

6. Nguyễn Hũu Phụng, 1992. Sách Đỏ Việt Nam. NXB Khoa học Kỹ thuật. 396 trang.

7. Perante, N. C., A. C. J Vincent \& M. G Pajaro, 1998. Demographics of the seahorse Hippocampus comes in the central Philippines. In Proceedings of the $3^{\text {rd }}$ International Conference on the Marine Biology of the South China Sea, pp. 439448. Hong Kong, China: Hong Kong University Press.

8. Perante, N. C., M. G Pajaro., J. J. Meeuwig \& A. C. J Vincent, 2002. Biology of a seahorse species Hippocampus comes in the central Philippines. Journal of Fish Biology 60, 821-837.

9. Vincent, A.C.J., 1996. The International trade in Seahorse. Cambridge, UK: TRAFIC Internatinal. 163 trang.

10. Woods, C. M. C., 2003. Effects of stocking density and gender segregation in the seahorse Hippocampus abdominalis. Aquaculture 218: 167-176.

11. Woong J. M. and J.A.H. Benzie, 2003. The effects of temperature, Artemia enrichment, stocking density and light on the growth of juvenile seahorse Hippocampus whitei (Bleeker, 1855), from Australia. Aquaculture 228: 107-121. 


\title{
THE EFFECTS OF STOCKING DENSITY ON JUVENILE GROWTH AND SURVIVAL RATE OF TIGER TAIL SEAHORSE (HIPPOCAMPUS COMES CANTOR, 1850 ) IN KHANH HOA WATERS
}

\author{
TRUONG SI KY, HOANG DUC LU, HO THI HOA, PHAM VU LANG
}

\begin{abstract}
Summary: The effects of stocking density on juvenile growth and survival rate of Tiger tail seahorse (Hippocampus comes) were examined over 105 days. The initial length of seahorse is $39.06 \mathrm{~mm}, 39.26 \mathrm{~mm}$ and $39.73 \mathrm{~mm}(P>0.05)$ in trials 50 ind./150 liters (set1), 100 ind./ 150 (set 2) and 150 ind./ 150 liters (set 3), respectively. After 105 days of experiment, the final length of seahorse reaches $94.40 \mathrm{~mm}, 89.95 \mathrm{~mm}$ and $91,00 \mathrm{~mm}$ in set 1, 2 and 3 , respectively.

Growth rate was higher for cultured seahorse with density 50ind./150 liters than for the density 100 ind./150 and 150 ind./150 liters treatments $(P<0.05)$. Survival rate of seahorse in all trials was higher than $96 \%(P>0.05)$. This experiment demonstrates that growth rate of seahorse is the best when they are cultured with density 1 ind. in 3 liters of sea water.
\end{abstract}

Ngày nhận bài: 10 - 02 - 2010

Ngưòi nhận xét: PGS. TS. Nguyễn Hữu Phụng 